\title{
The Influence of Cultivar, Rootstock and Culture System on Growth and Yield in Apple
}

\author{
Dorin BADIU ${ }^{1)}$, Ioana MITRE $\mathrm{jr}^{1)}$, Andreea TRIPON ${ }^{1)}$, Ioana MITRE ${ }^{1)}$, Viorel MITRE ${ }^{1^{*}}$ ) \\ ${ }^{1}$ Faculty of Horticulture, Agricultural Sciences, University of Agricultural Sciences and Veterinary \\ Medicine Cluj-Napoca \\ ${ }^{*}$ corresponding author, e-mail: mitre.viorel@usamvcluj.ro
}

BulletinUASVM Horticulture 72(1) / 2015

Print ISSN 1843-5254, Electronic ISSN 1843-5394

DOI:10.15835/buasvmcn-hort:11091

\begin{abstract}
The influence of two apple rootstocks (M9 and MM106) on growth and yielding of four apple cultivars („Pinova”, „Topaz”, „Florina” and „Golden Reinders”) in two culture system was studied. The experiment was placed in a commercial orchard at SC Agroindustriala Cluj-Napoca Romania, planted in 2007, during 2012-2104. In the experimental field some growth parameters (length of annual shoots, trunk cross-sectional area, tree height) and fructification (average yield and productivity index) were observed. The studied cultivars had a different response due to the genetic characteristic of each one and on the other hand, due to the rootstock. The results showed that MM 106 transmit much strongly growth than M9. The longest shoots, in terms of mean values, gave the variants where the cultivars were grafted on MM106 $(53 \mathrm{~cm})$ and the shortest $(34.4 \mathrm{~cm})$ on M9. The biggest average height of trees were obtained on MM 106 rootstock $(290 \mathrm{~cm})$. The smallest average trees height were registered by the variants where the trees were grafted on M9 $(239 \mathrm{~cm})$. The biggest average trunk cross sectional area were obtained with the MM106 (102.1 cm2). The best yield was obtained in variant where the cultivars were grafted on M9 (47.03 t/ha). M9 rootstock has controlled the tree size of all cultivars more than MM106 resulting in the lowest TCSA (58.8 $\mathrm{cm}^{2}$ ) and the highest yield per hectar (47.03 tone/ha) and yield efficiency $\left(925 \mathrm{~kg} / \mathrm{cm}^{2}\right)$.
\end{abstract}

Keywords: rootstock, yield, M 9, MM 106

\section{INTRODUCTION}

Achieving maximum biological potential of growth and fructification of a cultivar is strongly influenced by the combination of cultivar/ rootstock. This combination determines the culture system (intensive or superintensive) and the complex of technological measures that influence directly production and fruit quality.

Each system has own advantages and disadvantages. High density plantations are characterized by earlier production, aiming for commercially acceptable yields from the third year, higher yield potential per hectare, higher and more uniform fruit quality, earlier return of investment, easyness of picking, as fruit is easy to see, and easyness of the access to the canopy.
However, it is very important to know all these aspects for each combination before establish a plantation.

The use of intensive orchards has been proposed to improve profitability and yield, notably of early cropping, in apple orchards (Lauri et al., 2004)

Trees must be trained and pruned in order to achieve a manageable uniform size, a balance between growth and regular yield, and to allow good penetration of light and spray to the tree center (Malavolta and Cross, 2009).

In addition, fruit color is often poor in the center of the canopy of large trees (Mohammad etal., 2012). This aspect is often observed in apple orchards grafted on MM106. 
Small trees of uniform sizes represents the goal for the future so that safer, more efficient spraying practices can be adopted. Trees must be trained and pruned accordingly to achieve a manageable uniform size, a balance between growth and regular yields, and to allow good penetration of light and spray to the tree centre (Malavolta and Cross, 2009).

Research on apple trees using dwarf rootstocks in intensive planting systems has been carried out in different countries (Barritt et al., 1995).

The switch to smaller trees and higher tree planting densities has allowed significant improvements in fruit quality (Robinson, 2007).

In modern orchards, planting systems are based on higher tree densities with 10006000 trees/ha and some up to 10000 trees/ha (Robinson, 2003).

Modern orchards planting systems are based on higher tree densities with a range from 1000 to 6000 trees per hectare and some up to 10000 trees per hectare (Robinson, 2003).

However, increasing only planting density does not increase yield, as planting density and yield are not linearly related and a threshold can be found beyond which a further increase in density may not result in greater yield (Webster, 2001; Hampson et al., 2002).

Clonal dwarfing rootstocks for apple control scion growth by the reduction of canopy spread, branches compression and tree height. M9 has been introduced as a dwarf rootstock that induces excellent yield, precocity, efficiency and large fruit size.

The manner in which plant management systems are applied has direct implications over the planting density, the degree of fruit exposure and quality (Caprariu and Gradinariu, 2009).

Small sized crowns allow the fruit grower to perform the main manual works from the ground, with greater yield and lower percentage of the manual works in the production costs (Hoza et al., 2012).

The successful balance of vegetative vigor and fruiting results in 'calm' trees that produce heavy annual crops and require only a light annual pruning.

The goal of modern high-density orchard systems is to achieve high yield at early tree age (Cody et al., 1985; Jaumien et al., 1993; Theron et al., 2000).
The aim of this investigation were to study the influence of two apple rootstocks having different vigour (vegetative M9 and MM106 rootstocks), recommended for different culture systems on the performance of growth and fruiting of four apple cultivars with great spread in production, in order to determine which of them give higher performance.

\section{MATERIALS AND METHODS}

The experimental field was placed in a commercial orchard at SC Agroindustriala ClujNapoca Romania, planted in 2007 with four apple cultivars „Pinova”, „Florina”, „Topaz”and „Golden Reinders" grafted on clonal rootstocks MM106 and M9.

The trees were planted in two different culture systems: first one at distance of $4 \mathrm{~m}$ between rows and $2 \mathrm{~m}$ between trees in the row, with a density of 1250 trees/ha where trees were grafted on MM106 and the second one at distance of $3.5 \mathrm{~m}$ between the rows and $0.9 \mathrm{~m}$ between trees in the row with a density of 3175 trees/ha where the trees were grafted on M9.

The area has a temperate continental climate with an average annual rainfall of $530 \mathrm{~mm}$. The orchard was established in spring of 2007, with high-quality 1-year-old nursery trees that presented 6 or more lateral branches.

The experiment was done on 12 representative trees within each replication. The plot design was used for statistical analysis on a randomized complete block (RCBD) with four replications.

In order to register the shoots growth, the average current season growth of six branches in each tree at the end of the seasonal growth was measured $(\mathrm{cm})$.

Also, in order to measure the tree height, distance between graft unions to end of highest branch in main trunk was recorded in $\mathrm{cm}$. In addition, yield per tree was recorded at harvest time in each tree.

For calculating the Trunk Cross Sectional Area (TCSA), trunk diameter $(20 \mathrm{~cm}$ above the graft union) was measured twice at the beginning of March at $30 \mathrm{~cm}$ above the grafting union. Yield per tree was calculated on the amount of fruit in each tree at harvest time. Yield efficiency was measured as yield per tree divided to TCSA. 
Analysis of variance (ANOVA) and mean separations by Duncan's multiple range test were performed.

\section{RESULTS AND DISCUSSION}

The successful management of apple trees depends on maintaining a balance between vegetative growth and fruiting. If vigor is low, excessive fruiting results, fruit size increase, biennial bearing increase too. If vegetative vigor is excessive then flowering and fruiting are reduced and also the yield.

The growing system and the rootstock had an important influence upon average length of annual growth in the experimental field with statistically assured differences. Regardless the cultivar, the longest shoots, in mean values, gave the variants where the cultivars were grafted on MM106 (53 $\mathrm{cm})$ and the shortest $(34.4 \mathrm{~cm})$ on $\mathrm{M} 9$ rootstock (Tab.1.).
All cultivars behaved similarly regarding the average length of shoots without differences statistically assured between them. The highest value of shoots average in „Florina” $(54.5 \mathrm{~cm})$, followed by „Pinova” (42.6 cm) and "Golden Reinders" $(39.5 \mathrm{~cm})$ was registered. Taking into account the combined action of two experimental factors, one can say that the longest shoots was obtained in combination "Florina” grafted on MM106 $(69.3 \mathrm{~cm})$ and the shortest shoots at „Pinova” grafted on M $9(30.5 \mathrm{~cm})$. The influence of cultivar and rootstock on average height of trees is presented in Table 2. Analyzing data from this table, one can see that the rootstock influenced obviously the average height of trees.

The biggest average height of trees with the MM106 rootstock were obtained $(290 \mathrm{~cm})$. The smallest average height of trees with the variants where the trees were grafted on M9 $(239 \mathrm{~cm})$ was registered too. Data from the last column of the

Tab.1. The influence of cultivar and rootstock on average length of shoots $(\mathrm{cm})$

\begin{tabular}{|c|c|c|c|}
\hline $\begin{array}{c}\text { Rootstock } \\
\text { Cultivar }\end{array}$ & MM 106 & M 9 & Mean Cultivar \\
\hline „Pinova” & $54.8^{\mathrm{a}}$ & $30.5^{\mathrm{ab}}$ & $42.6^{\mathrm{a}}$ \\
\hline „Florina” & $69.3^{a}$ & $39.8^{a b}$ & $54.5^{\mathrm{a}}$ \\
\hline „Topaz” & $43.0^{\mathrm{a}}$ & $33.5^{\mathrm{ab}}$ & $38.3^{a}$ \\
\hline „Golden Reinders” & $45.0^{\text {a }}$ & $34.0^{\mathrm{ab}}$ & $39.5^{\mathrm{a}}$ \\
\hline Mean rootstock & $53.0^{\mathrm{M}}$ & $34.4^{N}$ & \\
\hline LSD 5\% Cultivar =13.7-14.8 & LSD5 \% Rootstock = 9.7 & LSD5\% interactic & $\mathrm{ock}=19.4-22.8$ \\
\hline
\end{tabular}

Note $^{*}=$ the difference between any two values followed by at least one common letter is not significant

Tab.2. The influence of cultivar and rootstock on average height of trees (cm)

\begin{tabular}{|c|c|c|c|}
\hline Cultivar & MM 106 & M 9 & Mean Cultivar \\
\hline „Pinova” & $271^{\mathrm{b}}$ & $226^{c}$ & $248^{A}$ \\
\hline „Florina” & $339^{a}$ & $277^{b}$ & $308^{c}$ \\
\hline „Topaz” & $266^{b}$ & $220^{c}$ & 243 Ав \\
\hline „Golden Reinders” & $284^{b}$ & $232^{c}$ & $258^{A}$ \\
\hline Mean rootstock & $290^{\mathrm{M}}$ & $239^{N}$ & \\
\hline LSD5\% cultivar 12.2-13.2 & LSD5\% rootstock = 8.6 & LSD5\% interact & $\mathrm{ck}=17.2-20.3$ \\
\hline
\end{tabular}

Note $^{*}=$ the difference between any two values followed by at least one common letter is not significant 
table show that for the average height of trees, there are statistically assured differences between the cultivars.

These differences could be explained only from genetically point of view. The biggest average height of trees was obtained by „Florina” $(308 \mathrm{~cm})$ and the smallest by „Topaz” $(243 \mathrm{~cm})$.

Data inside the table shows the combined influence of two experimental factors. The biggest average height of trees with „Florina” and MM 106 rootstock was registered and the smallest with „Topaz” and M9.

Analyzing data from the Figure 2, one can see that the rootstock influenced the surface of the trunk section. The biggest average trunk cross sectional area with the MM106 were obtained $\left(102.1 \mathrm{~cm}^{2}\right)$.

The smallest TCSA was registered with M9 rootstock. Data from the top part of the figure show that between the cultivars there are differences statistically assured regarding the TCSA.

These differences could be explained also from genetically point of view. Data from the bottom part of the figure shows the combined influence of two experimental factors. The biggest average TCSA has been noticed with „Florina” grafted on MM 106 and the smallest with „Pinova” grafted on M9.

The yield is by far the most important indicator that reflects the performance of orchards. Tabel 3 introduce data referring to the influence of cultivars and rootstocks on average yield of the apple tree.

Following the data of next table, it could be observed that the best yield was obtained in variant where the cultivars were grafted on M9 (47.03 t/ha) with statistically differences assured. Regardless the cultivar, the smallest yield gave the variants grafted on MM106.

Looking to the data of mean cultivar in the table 3 , it can be seen that there were no differences statistically assured between cultivars. The bigest yield gave "Florina” $(38951 \mathrm{~kg} / \mathrm{ha})$ and the lowest „Topaz” (35303 kg/ha). Regarding to the combined influence of two experimental factors the best yield was obtained at „Pinova”/M9 followed by „Florina” and „Golden Reinders” also on M9.

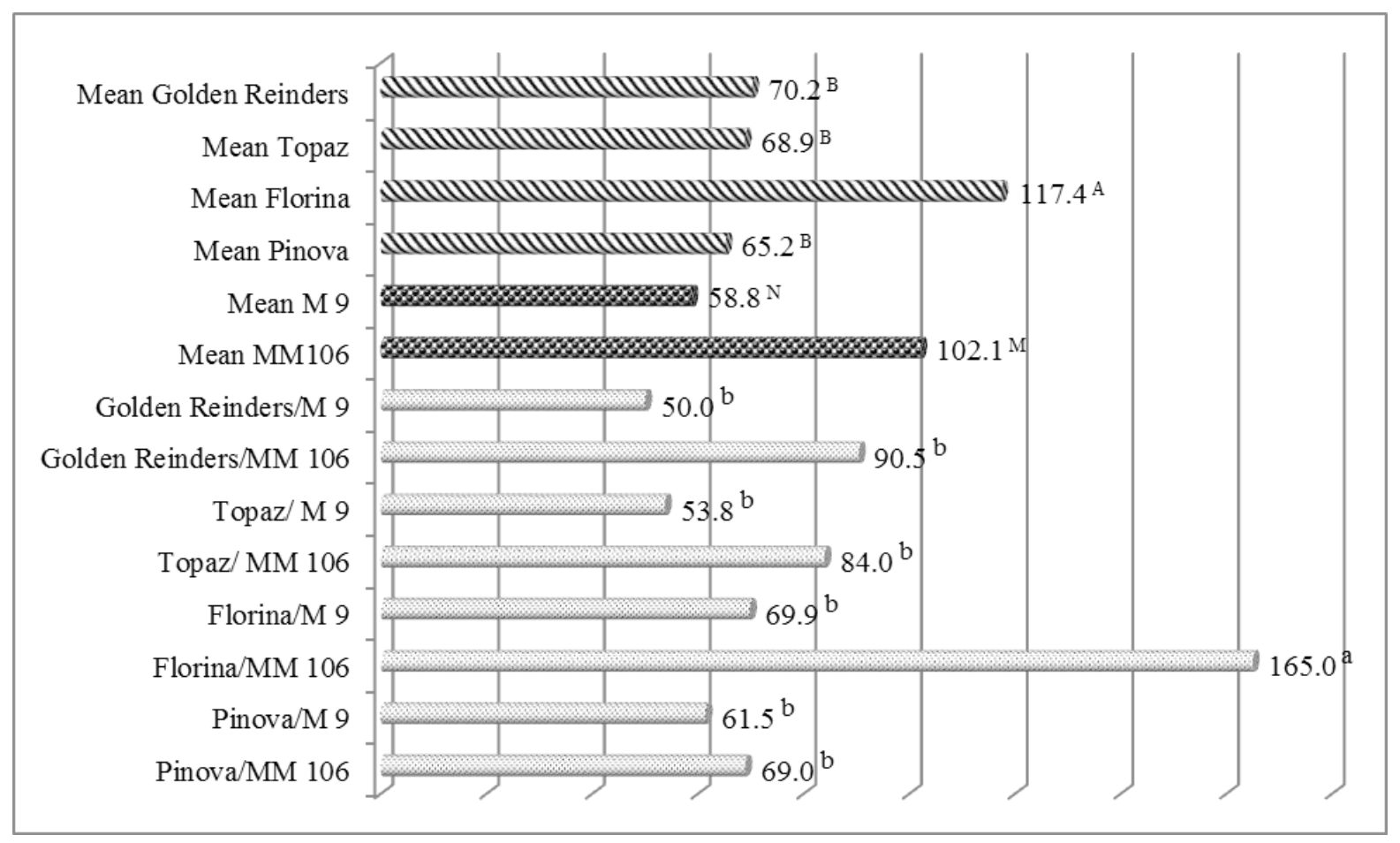

Note $*$ the difference between any two values followed by at least one common letter is not significant

Fig. 1. The influence of rootstock and cultivar on TSCA $\left(\mathrm{cm}^{2}\right)$ 
The beneficial effects of dwarfing rootstock on the precocity and efficiency of tree yields have often been attributed to a change in the partitioning of the dwarfed trees assimilate from shoot growth to fruit production (Mohammad et al., 2012)

Results presented in Fig.2. showed that cultivars grafted on M9 had a more yield efficiency (925 $\mathrm{kg} \mathrm{cm}^{2}$ ) than MM106 (356 $\mathrm{kg} \mathrm{cm}^{2}$ )

Increased photosynthesis and yield efficiency in grafted cultivars on dwarfing rootstock deriving from reduction of shoot growth vegetative, competition between vegetative and productive growth, more light penetration in canopy and intensity in area unit (Avery, 1970; Webster, 2001 McAfee \& Rom, 2003) is demonstrated.

Differences in TCSA indicate that rootstock controls the tree size (Dolp \& Proebsting, 1989). In fact, the results of the present study confirme that the M9 rootstock has controlled the tree size of all cultivars more than MM106, resulting in the

Tab.3. The influence of cultivar and rootstock on average yield, ( $t / h a)$,

\begin{tabular}{cccc}
\hline Rootstock & MM 106 & M 9 & $\begin{array}{c}\text { Mean } \\
\text { Cultivar }\end{array}$ \\
\hline Cultivar & $23.598^{\mathrm{c}}$ & $51.563^{\mathrm{a}}$ & $37.580^{\mathrm{A}}$ \\
\hline „Pinova” & $27.742^{\mathrm{c}}$ & $50.161^{\mathrm{a}}$ & $38.951^{\mathrm{A}}$ \\
\hline „Florina” & $28.255^{\mathrm{c}}$ & $42.352^{\mathrm{ab}}$ & $35.303^{\mathrm{A}}$ \\
\hline „Topaz” & $28.737^{\mathrm{c}}$ & $44.080^{\mathrm{a}}$ & $36.409^{\mathrm{A}}$ \\
\hline "Golden Reinders” & $27.083^{\mathrm{N}}$ & $47.03^{\mathrm{M}}$ & \\
\hline Mean rootstock & &
\end{tabular}

DS $5 \%$ cultivar $=5.5-6.0$

DS $5 \%$ rootstock $=3.9$

DS $5 \%$ cultivar $\mathrm{x}$ rootstock $=7.8-9.2$

Note $^{*}=$ the difference between any two values followed by at least one common letter is not significant

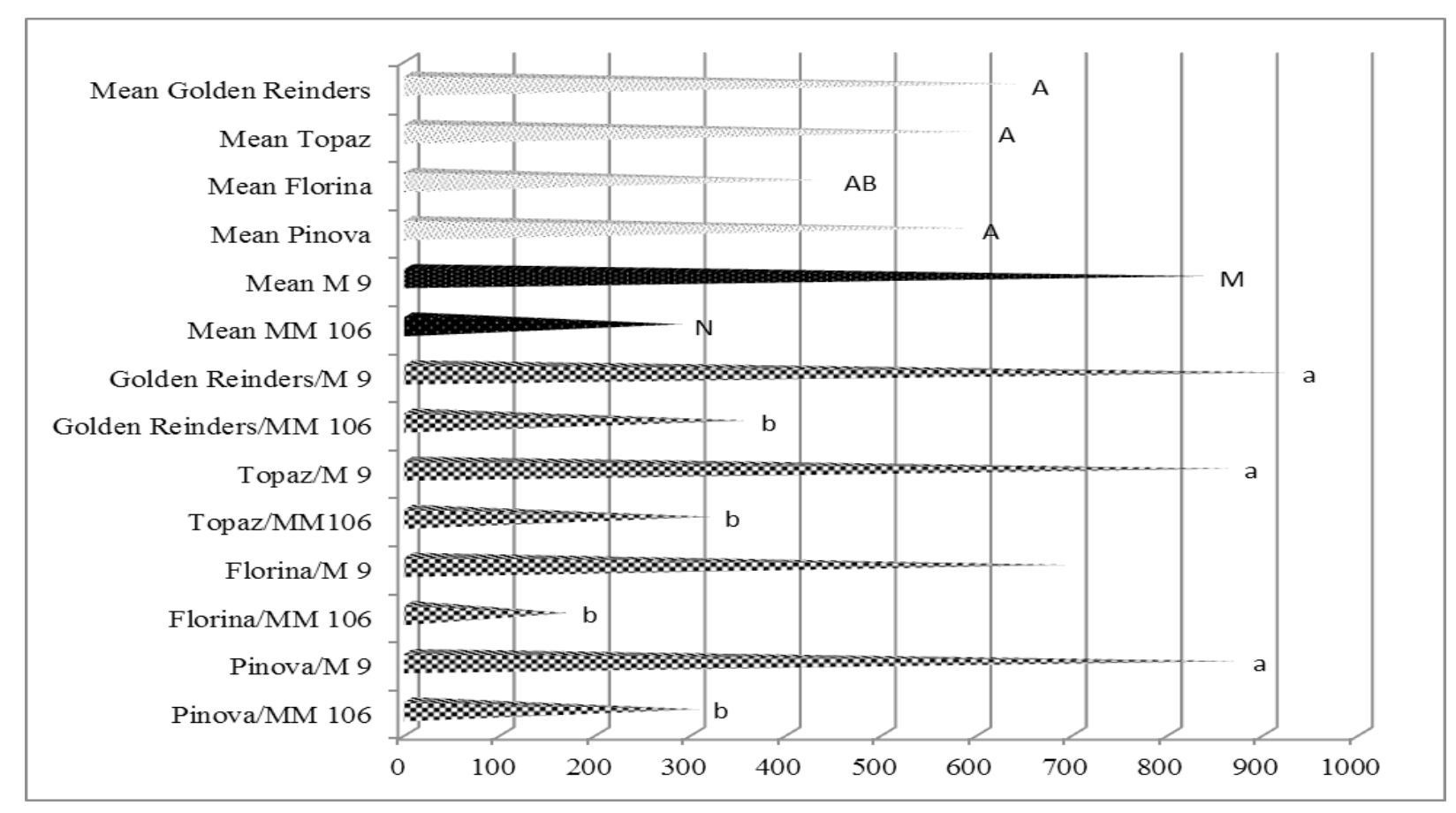

Note $*$ the difference between any two values followed by at least one common letter is not significant

LSD 5\% cultivar $=237-256 \quad$ LSD5 \% rootstock $=168 \quad$ LSD5\% interaction $\mathrm{cV} . \times$ rootstock $=335-394$

Fig. 2. The influence of rootsock and cultivar on productivity index $\left(\mathrm{kg} / \mathrm{cm}^{2}\right)$ 
lowest TCSA $\left(58.8 \mathrm{~cm}^{2}\right)$ and the highest yield per hectar (47.03 tone/ha) and yield efficiency (925 $\left.\mathrm{kg} / \mathrm{cm}^{2}\right)$.

\section{CONCLUSION}

The obtained results indicated that each cultivar has specific response strongly influenced by rootstock.

MM106 rootstock caused much greater vegetative growth disturbing balance between growth and fruiting in the first years of fruit.

M9 rootstock gave lower vegetative growth, which evolved into fruits, favoring the balance between growth and fruiting in the first years of fruiting.

Lower vegetative growths led to a lower volume of crowns and a lower height of trees, which makes trees to be easier to maintain.

For all this reasons, cultivation of apple grafted on M9 in high density culture has proven superiority both in terms of management but also through the trees fruits production and productivity index obtained.

Acknowledgments. This paper was published under the frame of European Social Fund, Human Resources Development Operational Programme 2007-2013, Project POSDRU 159/1/5/S/132765

\section{REFERENCES}

1. Avery DJ (1970). Effects of fruiting on the growth of apple trees on four rootstock varieties. New Phytologist . 69 (1):19-30.

2. Barritt BH, Konishi AS, Dilley MA (1995). Intensive orchard management. Performance of three apple cultivars with 23 dwarfing rootstocks during 8 seasons in Washington. Fruit Var. J. 49 (3):158-170.

3. Capraru F, Gradinariu G (2009). Research on productivity of apple varieties in different technological sequences in climatic conditions from Bistrita. Scientific papers, year
- vol LII . 52, Series Horticulture, Ed. Ion Ionescu de la Brad, Iasi:545- 550.

4. Cody C, Larsen FE, Fritts R (1985). Induction of lateral branches intree fruit nursery stock with propyl 3-t+butylphenoxy acetate 8MB 25, 105) and promalin (GA4+7+6 benzyladenine). Scienta Hort., 26:116-8.

5. Dolp CA, Proebsting EL (1989). Root confinement effects growth and physiology of sweet cherry and apple. 50th ASHS Ann. Meeting, Tulsa, Oklahoma, Prog. \& Abstract.:99.

6. Hampson CR, Quamm HA, Brownlee RT (2002). Canopy growth, yield and fruit quality of Royal Gala apple trees grown for eight years in five tree training systems. HortScience. 37:627-631.

7. Jaumien FB, Czarnecki T, Mitrut T, W. Poiedzialek W, 1993. Very similar effects of a mixture of GA3 and BA (6-benzylaminopurine) and of Ga4+7 and BA on branching of some apple cultivars in nursery. Acta Hort., 329: 35-42.

8. Lauri PE, Willaume M, Larrive G, Lespinasse JM (2004). The concept of centrifugal training in apple aimed at optimizing the relationship between growth and fruiting. Acta Hort 636:35-42.

9. Malavolta C and Cross J (2009). Guidelines for integrated production of pome fruits. IOBC/WPRS Bulletin 47. 1-13.

10. McAfee JD, Rom CR (2003). Evaluation of size- Controling apple rootstock for high density 'Gala' apple orchards in Arkanass Horticultural studies. Department of Horticulture, University of Arkanass.:21-23.

11. Mohammad RD, Mohammad J S, Zeinab H (2012). Effects of M9 and MM106 rootstocks on agromorphological characteristics of 'Golab kohanz' and 'Delbarstival' apple cultivars in Abhar region of Iran. Indian J.Sci.Technol. 12(1), 2012.

12. Robinson TL (2003). Apple-orchard planting system. In: Apples (eds.), Ferree DC \& Warrington IJ (Eds), Cabi Publ., Wallingford, UK.:345-407.

13. Robinson TL (2007). Recent advances and future directions in orchard planting systems. Acta Hort. 732:367-382.

14. Theron KI, Steyn WJ, Jacobs G (2000). Induction of proleptic shoot formation on pome fruit nursery. Acta Hort., 514:235-43.

15. Webster AD (2001). Rootstocks and temperate fruit crops: current uses, future potenial and alternative.Acta Hort. 557:25-34 